\title{
Delaration of Madrid: position statement on the provison of critical care nursing education
}

\section{INTRODUCTION}

At the 6th World Congress on Intensive Care and Critical Care Medicine in Madrid, Spain 1993 the World Federation of Societies of Intensive Care and Critical Care Medicine endorsed what has become know as the Declaration of Madrid on the preparation of critical care nurses.

In May 2003 the World Federation of Critical Care Nurses undertook a review of the Declaration of Madrid and recommendations from the Australian College of Critical Care Nurses position statement on critical care nursing education and other similar documents from member associations. The current position statement aims to inform/assist critical care nursing associations, health care providers, educational facilities and other interested parties in the development and provision of critical care nursing education.

The first draft of this position statement was distributed to member societies of the WFCCN between February 2004 and September 2004 and changes made following discussion and meeting of the WFCCN in Cambridge September 2004. The second draft of this position statement was distributed to a wider audience including member societies of WFCCN, other international nursing and medicine organisations and individuals with an interest in critical care nursing between October 2004 and April 2005. The third draft of this position statement was distributed to an ever-wider audience again including member societies of WFCCN, other international nursing and medicine organisations and individuals with an interest in critical care nursing between May2005 and August 2005.

A full meeting of the World Federation of Critical Care Nurses on Saturday 27 August 2005 at the Sheraton Hotel, Buenos Aires, Argentina, ratified this position statement.

\section{Copyright}

Copyright of this statement is owned by WFCCN. Whilst this statement is freely available for all people to access, its wording may not be changed under any circumstances.

\section{PREAMBLE}

Critical or intensive care is a complex specialty developed to serve the diverse health care needs of patients (and their families) with actual or potential life threatening conditions.

The role of the critical care nurse is essential to the multidisciplinary team needed to provide specialist knowledge and skill when caring for critically ill patients. The critical care nurse enhances delivery of a holistic, patient centred approach in a high tech environment bringing to the patient care team a unique combination of knowledge and caring. In order to fulfil their role, nurses require appropriate specialised knowledge and skills not typically included in the basic nursing programs of most countries.
Government, professional and educational bodies governing the practice of nursing must recognise the importance of dedicated specialised preparation for critical care nurses in order to assure the optimum health care delivery of their community. This declaration presents guidelines universally accepted by critical care professionals, which may be adapted to meet the educational and health care requirements of a particular country or jurisdiction.

\section{CENTRAL PRINCIPLES}

1. Critically ill patients and families have the right to receive individualised critical care from qualified professional nurses.

2. Critical care nurses must possess appropriate knowledge, attributes and skills to effectively respond to the needs of critically ill patients, to the demands of society, and to the challenges of advancing technology.

3. Where a basic nursing education program does not include these required specialised knowledge, attributes and skills, access to such further education must be provided to nurses responsible for the care of critically ill patients and their families.

4. Nurses with specialised knowledge and expertise in the provision of care to critically ill patients should play an integral part in the education of critical care nurses, even when a multidisciplinary, educational approach is utilised.

5. The preparation of critical care nurses must be based on the most current available information and research.

\section{RECOMMENDATIONS FOR CRITICAL CARE NURSING EDUCATION}

The World Federation of Critical Care Nurses believes that critically ill patients have very special needs and must be cared for by nurses with specialist skills, knowledge and attitudes.

The following recommendations have been adopted to represent universal principles to help guide health services, educational facilities and critical care nursing organisations in the development of appropriate educational programs for nurses who are required to care for critically ill patients and their families:

1. As a minimum, the critical care dimensions of the following topics should be included in programs to prepare critical care nurses. The categories are not listed in order of importance.

- $\quad$ Anatomy and physiology

- Pathophysiology

- Pharmacology

- $\quad$ Clinical Assessment (including interpretation of diagnostic and laboratory results)

- Illnesses and alterations of vital body functions 
- $\quad$ Plans of care and nursing interventions

- Medical interventions and prescriptions with resulting nursing care responsibilities

- $\quad$ Psychosocial aspects (including cultural and spiritual needs)

- $\quad$ Technology applications

- $\quad$ Patient and family education

- $\quad$ Legal and ethical issues

- Professional nursing issues and roles in critical care, including clinical teaching strategies, team leadership and management issues

- $\quad$ Use of current research findings to deliver evidence based multidisciplinary care

- $\quad$ Caring for the carer (including dealing with stress and peer support)

2. Programs preparing critical care nurses to function at a specialist level of practice should be provided at a post-registration level and conducted by a higher education provider (for example, a university or equivalent provider).

3. The curricula of critical care nursing post-registration courses must provide an appropriate mix of theoretical and clinical experience, to prepare nurses to meet the challenges of clinical practice effectively.

4. WFCCN recommends that national critical care nursing associations establish agreed Standards for Specialist Critical Care Nursing to be utilised as a framework for both critical care curriculum development and assessment of clinical practice.

5. Post-registration courses for critical care nurses must provide a balance between clinically oriented content and broader generic content that enables the specialist nurse to contribute to the profession through processes such as research, practice development and leadership.

6. Close collaboration between the health care and higher education sectors is important, in order that post-registration critical care nursing education be provided at a standard that meets the expectations of both sectors.

7. Graduates of post-registration courses in critical care must be able to demonstrate clinical competence as well as a sound theoretical knowledge base. A strong emphasis on the application of theory to practice, and the assessment of clinical competence, should be an integral component of post-registration critical care courses.

8. The provision of appropriate clinical experience to facilitate the development of clinical competence should be a collaborative responsibility between education and health care providers. Critical care nursing students should have access to support and guidance from appropriately experienced staff such as clinical teachers and nurse preceptors.

9. Clinical teachers and nurse preceptors for post-registration critical care nursing students should be appropriately supported in their role by both education and health care providers.

10. Critical care education providers should have in place policies and processes for recognition of prior learning and alternative entry pathways into formal post-registration specialist courses, in order to create a more flexible yet consistent means for students to attain recognition of competence.

11. Health care and higher education providers need to establish strategies to help reduce the financial burden faced by nurses undertaking post-registration critical care courses.

12. Education providers must implement educational strategies to facilitate access to post-registration courses for critical care nurses from a range of geographical locations.

13. Innovative strategies need to be implemented to address the deficit of qualified critical care nurses, rather than resorting to short training courses to resolve the problem. Such strategies could include comprehensive critical care workforce planning, innovative retention strategies, refresher 'training', professional development programs and the provision of greater support for nurses undertaking post-registration critical care courses.

14. Providers of short critical care training courses should seek credit transfer (recognition of prior learning) within the higher education sector for nurses completing these courses.

\section{References}

Australian College of Critical Care Nurses (1999). Critical Care Nursing Education Advisory Committee, Position Statement on postgraduate critical care nursing education - October 1999. Australian Critical Care 12(4):160-164.

International Nursing Council (2004). The Global Shortage of Registered Nurses: An Overview of Issues and Actions (and accompanying Issues Papers). [Online] Available at: www.icn.ch/global/\#3

World Federation of Societies of Intensive and Critical Care Medicine (1993). Declaration of Madrid on the preparation of critical care nurses. Australian Critical Care 6(2): 24. 